\title{
Matrix Optimization of Ultra High Performance Concrete for Improving Strength and Durability
}

\author{
Julio Paredes ${ }^{1}$, Jaime C. Gálvez ${ }^{1, *}$ Alejandro Enfedaque ${ }^{1}$ and Marcos G. Alberti ${ }^{1}$ \\ 1 Departamento de Ingeniería Civil: Construcción, E.T.S de Ingenieros de Caminos, Canales y Puertos, \\ Universidad Politécnica de Madrid, c/Profesor Aranguren, s/n, 28040 Madrid, Spain; \\ julparedes@gmail.com; Jaime.galvez@upm.es; alejandro.enfedaque@upm.es; marcos.garcia@upm.es. \\ * Correspondence: Jaime.galvez@upm.es (J.C.G.)
}

\begin{abstract}
This paper seeks to optimize the mechanical and durability properties of ultra-high performance concrete (UHPC). To meet this objective, concrete specimens were manufactured by using $1,100 \mathrm{~kg} / \mathrm{m}^{3}$ of binder, water/binder ratio 0.20 , silica sand and last generation of superplasticizer. Silica fume, metakaolin and two types of nano silica were used for improving the performances of the concrete. Additional mixtures included $13 \mathrm{~mm}$ long OL steel fibers. Compressive strength, electrical resistivity, mercury intrusion porosimetry tests and differential and thermogravimetric thermal analysis were carried out. The binary combination of nano silica and metakaolin, and the ternary combination of nano silica with metakaolin and silica fume, led to the best performances of the UHPC, both mechanical and durable performances.
\end{abstract}

Keywords: ultra high performance concrete (UHPC); concrete; compression strength; durability; nano additions; additions.

\section{Introduction}

Research developed in recent decades has led significant advances in concrete technology that has enabled a continuous increase of the performances of concrete, mainly based on the improvement of the microstructure. The demand for concretes with improved performance changes the traditional approach to improving the mechanical properties of concrete. The terms such as high-strength concrete (HSC) and ultra-high strength concrete (UHSC) [1, 2] are less used. In the early 1990s Richard introduced the term "reactive powder concrete" (RPC) to refer to low porosity concretes with high compression strength, which does not use coarse aggregates and also adds small particle materials such as silica fume [3]. In the same decade, De Larrard used the term ultra-high performance concrete (UHPC) to describe concrete of similar characteristics to that described by Richard, but also including the concept of high packing density $[4,5,6]$.

Today, there is an almost general consensus to use the acronym UHPC to refer to a cement-based composite material that has high compression strength, above $150 \mathrm{MPa}$, which uses high amounts of cement, mineral additions with micrometric and nanometric particle sizes, fine aggregates with high $\mathrm{SiO}_{2}$ content and very low water/binder ratio, even less than 0.20 . The low water content requires the mandatory use of superplasticizer additives that allow to achieve better packaging of the particles of the composite material, and this provides greater fluidity and workability to the mixture [7]. This type of concrete, in addition to having a high compression strength, provides other competitive advantages, among which stands out for its excellent durability. The increased strength of the concrete matrix is associated with the reduction of porosity, greater homogeneity and the improvement of its microstructure, and these in turn have a direct relationship to durability [5, 8, 9].

When HPC or UHPC incorporate structural fibers that can partially or completely replace traditional steel reinforcement, the terms high or ultra-high performance fiber reinforced concrete (HPFRC and UHPFRC) [10] can be used. Fibers improve the ductility and brittle nature of plain (fiberless) concrete under tensile stresses, as well as increase energy absorption capacity after the first fissure. In this type of concrete, high-pressure compaction and heat treatments are often applied to 
speed up the hydration process, reduce voids and increase density, leading to even higher compression resistance [2, 11].

Pozzolanic materials, such as metakaolin, silica fume and nano silica are used as partial substitution of cement in mixing designs and are responsible for microstructure densification, porosity reduction and accelerating the clinker hydration process [12], resulting in improved concrete performance. The UHPC matrix densifies due to two types of phenomena: the pozzolanic reaction of these materials with calcium hydroxide, and the associated filler effect that is associated with the packaging density [13]. While it is true that both phenomena are inclusive of each other, it can be said that the filler effect usually occurs at an early age, while the pozzolanic reaction begins at a later age, the same one that is enhanced with $\mathrm{pH}$ and temperature.

Firstly, hydration of the clinker minerals (alite $\mathrm{C}_{3} \mathrm{~S}$, belite $\mathrm{C}_{2} \mathrm{~S}$, tri-calcium aluminate $\mathrm{C}_{3} \mathrm{~A}$, and tetra-calcium ferro aluminate $\mathrm{C}_{4} \mathrm{FA}$ ) occurs, forming phases of hydrated calcium silicate (C-S-H gel) and calcium hydroxide or portlandite $(\mathrm{CH})$. The amount of $\mathrm{CH}$ produced after hydration is limited by UHPC's own low water content and this in turn limits the pozzolanic reaction between portlandite and reactive particles from additions that produce other phases of C-S-H.

In addition, the use of particles with diameters of less order of magnitude than those used in conventional concretes, improve the density of packaging. The use of fine aggregates gives greater uniformity to the matrix, while additions and nano additions are able to fill the gaps among cement grains and other materials constituting the matrix, even if their particles have not reacted with $\mathrm{CH}$. Furthermore, on the surface of filler particles there is a phenomenon of nucleation of hydrated calcium silicate (C-S-H), this phenomenon that accelerates cement hydration is known as 'seeding effect' $[12,14]$ and directly influences the improvement of UHPC performance.

In order to maximize particle packaging, different models have been developed. In 1890, Feret proposed a law linking increased strength to increased compactness. In the 1930s, Andreasen and Andersen (A\&A) [17] presented a semi-empirical study on packaging continuous particle size distributions (PSD) and then Funk and Dinger [18] made an adaptation of this model (modified A\&A) considering the smaller particles that were supposed to be zero in the A\&A model. De Larrard developed the Solid Suspension Model (SSM) based on the Linear Packaging Density Model (LPDM), developed by Money in 1951, but considering a non-infinite but elevated viscosity. All these models have been adapted to be able to integrate into different software that allow the optimization of the packaging of particles used in UHPC. Actual packaging will always be less than ideal packaging based on closed hexagonal packaging, so models consider adaptations that can approximate the actual state $[4,6,15,16]$.

This study seeks to optimize the design of UHPC, combining high compression strength with improved durability, through the use of additions and nano-additions. In addition to compression strength tests, mercury intrusion porosimetry (MIP) and differential and thermogravimetric thermal analysis (ATD-TG) tests were performed. Such tests establish a correlation among the compression strength of various UHPCs, with the modification of porous network, and the formation of the different hydrated products in the UHPC matrix. In addition, electrical resistivity tests were carried out to indirectly measure the connectivity and size of pores and relate them to the distribution obtained in the MIP tests.

\section{Materials and Mix design}

For the different mixing dosages of UHPC, siliceous sand was used as the only aggregate, with a maximum particle size of $1 \mathrm{~mm}$, specific gravity between $2400-2600 \mathrm{~kg} / \mathrm{m}^{3}$ and $\mathrm{SiO}_{2}$ content above 98\%. Portland cement CEM I 52.5R, according EN 197-1 Standard, and produced by CEMEX Spain Operations, was used. This grey cement, composed mainly of clinker (95-100\% by mass), is characterised by reaching a high compressive strength at early ages. Several types of additions and nano additions were employed in the different mixes produced: metakaolin (MK), silica fume (SF) and two types of nanosilica ( $\mathrm{NS}_{1}, \mathrm{NS}_{2}$ ), named Aerosil OX-50 and Aerosil 200, respectively. MK is a highly reactive pozzolanic metakaolin, produced by thermal activation of high purity kaolin clay, composed of micron-sized particles, manufactured by SIKA under the name of Metamax. SF is 
composed by non-porous amorphous spheres of $\mathrm{SiO}_{2}$ with submicron sizes of approximately 0.15 microns and specific surface area of $15-30 \mathrm{~m}^{2} / \mathrm{g}$, which tend to agglomerate reaching particle sizes up to 1 micron. It was manufactured by Elkem with the name of Elkem Microsilica 940U. NS 1 has an average particle size of 40 nanometers and a specific surface area of $35-65 \mathrm{~m}^{2} / \mathrm{g}$. NS 2 has an average particle size of 12 nanometers and a specific surface area of $175-225 \mathrm{~m}^{2} / \mathrm{g}$. The granulometry of the additions can be seen together with the cement in Figure 1. Moreover, the D50 particle size and the specific surface can be seen in Table 1

The water used was from the drinking water supply system of Madrid. Due to the low water content in the mixes, a superplasticizer of the PCE type (polycarboxylate ether) was used, capable of dispersing the particles of materials and improving the workability of the mixtures. This product is a slightly viscous yellowish liquid, with a density of $1080 \mathrm{~kg} / \mathrm{m}^{3}$, manufactured by Sika under the name of Sika Viscocrete 20-HE. Such product was used to achieve the spread diameter desired in the mixes. In the case of the fibre reinforced mixes, Dramix OL 13/0.20 steel fibres (13mm in length and $0.20 \mathrm{~mm}$ in diameter), were also incorporated. These fibres are manufactured from cold drawn high tensile steel wire and their dimensions and mechanical properties can be seen in Figure 2.

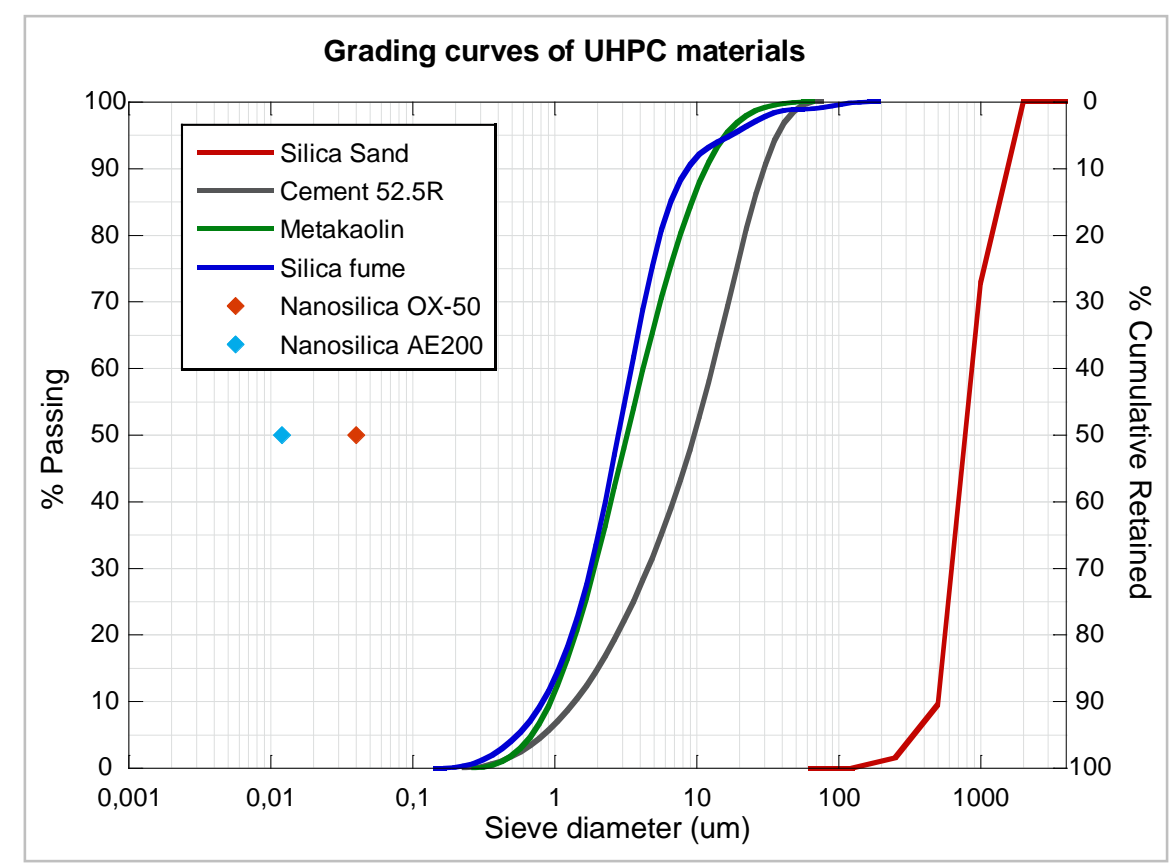

Figure 1. Grading curves of raw materials.

Table 1. D50 particle size and specific surface of raw materials.

\begin{tabular}{ccc}
\hline Material & $\begin{array}{c}\text { Particle } \\
\text { size } \mathbf{D}_{50}\end{array}$ & Specific surface area $\left(\mathbf{m}^{2} / \mathbf{g}\right)$ \\
\hline Silica sand 3 (0,7 mm) & $0.750 \mathrm{~mm}$ & \\
\hline Cement (type I - 52.5R) & $9.630 \mu \mathrm{m}$ & 1.31 \\
\hline Metakaolin (Metamax) & $3.240 \mu \mathrm{m}$ & 12.56 \\
\hline Silica fume (Norway SF) & $2.820 \mu \mathrm{m}$ & 21.59 \\
\hline Nano silica (Aerosil OX-50) & $0.040 \mu \mathrm{m}$ & $50 \pm 15$ \\
\hline Nano silica (Aerosil 200) & $0.012 \mu \mathrm{m}$ & $200 \pm 25$ \\
\hline
\end{tabular}




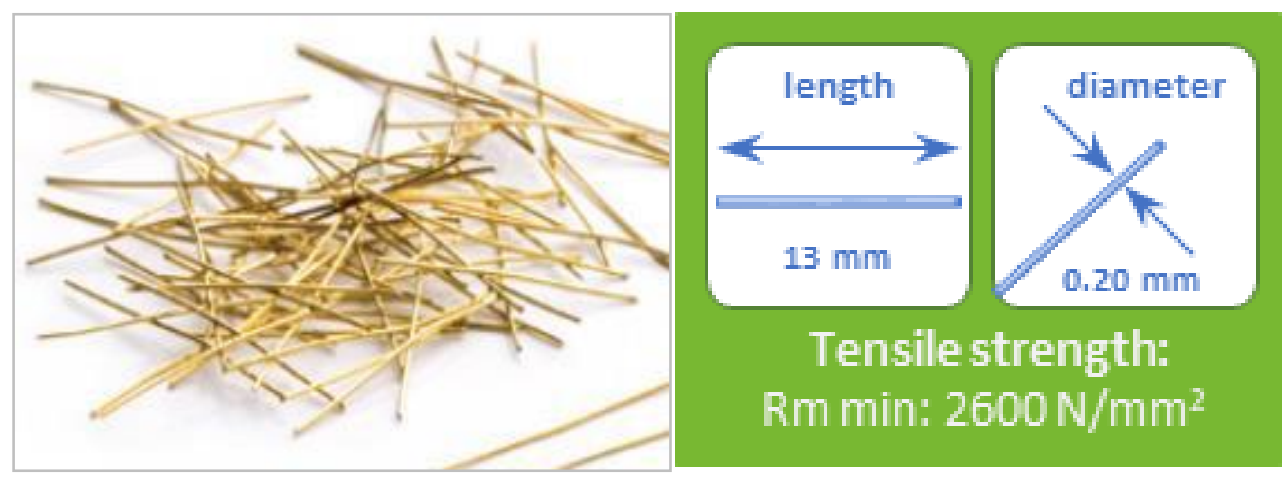

Figure 1. Dramix-OL steel fibres characteristics.

In previous studies $[1,2]$ it was seen that a remarkable improvement of the mechanical properties were obtained with a $10 \%$ substitution of MK, showing also a refinement of the concrete pore structure. Regarding the content of silica fume, it was observed that it could be obtained a significant enhancement of the mechanical properties replacing $10 \%$ of cement with SF [3]. Similarly, other studies highlighted that an increment in the concrete durability could be also achieved by replacing $10 \%$ of cement weight by SF [4]. In what concerns the use of nano additions, there are contributions that have pointed out that an improvement of the mechanical properties and durability could be obtained by using different replacements of cement which range from low amounts close to $1 \%$ up to $6 \%$ [5-7]. Even there are some publications that have studied the effect of the combination of ternary mixtures in the concrete durability when normal contents of cement are employed [8]. However, in almost all the aforementioned publications contents of cements below $500 \mathrm{~kg} / \mathrm{m}^{3}$ were used. Consequently, the effect of MK, SF and nano additions in UHPC mechanical properties and durability when used and combined in ternary, quaternary and quinary mixtures is a matter that deserves being studied.

Based on the previous studies mentioned, all the mixes performed were designed considering replacements around $10 \%$ of the cement weight. In all the mixtures, Viscocrete 20 HE superplasticizer was added in the amount necessary to obtain the same spread diameter on the shaking table. Different combinations of $\mathrm{MK}, \mathrm{SF}$, and $\mathrm{NS}_{1}$ and $\mathrm{NS}_{2}$ were employed seeking not only an improvement of the mechanical properties, but also of the durability. The reference mixture, which is named CONTROL was the base of the rest of them. It was manufactured in order to compare the influence of additions, nano additions and the combination of nano additions with traditional additions used for improving mechanical properties and durability of UHPC mixes. For this blend, 1,100 kg of cement per $\mathrm{m}^{3}$ of concrete, $1.60 \%$ of the cement weight of the superplasticizer additive and a watercement ratio of 0.20 was considered. The ratio volume of paste-volume/aggregate-volume was 1.27. The volume of paste represented $56 \%$ of the total volume of concrete, while the volume of aggregate, consisting only of silica sand, represented $44 \%$.

Three binary mixes were carried out, two of them with $8 \%$ and $10 \%$ of MK, which were called $8 \mathrm{MK}$ and $10 \mathrm{MK}$ and another one manufactured with $8 \%$ of SF termed $8 \mathrm{SF}$. Regarding the ternary mixes, two formulations were employed, the first one, where $10 \%$ of MK and $2 \%$ of Aerosil OX-50 were employed, which was named $10 \mathrm{MK}+2 \mathrm{NS} 1$, and the second one, where $4 \%$ of MK was mixed with $4 \%$ of SF, which was termed 4MK4SF. Moreover, two quaternary mixes were carried out. While one of them included $4 \%$ of MK, $4 \%$ of SF and $2 \%$ of Aerosil OX-50, which was called $4 \mathrm{MK} 4 \mathrm{SF}+2 \mathrm{NS} 1$ the other was termed $4 \mathrm{MK} 4 \mathrm{SF}+1.5 \mathrm{NS}_{1}$ and had a combination of $4 \%$ of $\mathrm{MK}, 4 \%$ of $\mathrm{SF}$ and $1.5 \%$ of $\mathrm{NS}_{1}$. Finally, a quinary mixture which comprised $4 \%$ of $\mathrm{MK}, 4 \%$ of $\mathrm{SF}$ and $2 \%$ of a combination of Aerosil OX-50 and Aerosil 200 was named 4MK4SF+2NS1-2. All the combinations performed can be seen in Table 1. In addition, to the mixes seen in Table 1, Dramix-OL fibres were added to the CONTROL and $4 \mathrm{MK} .4 \mathrm{SF}$ mixes in a $0.89 \%$ volumetric fraction. Such mixes were termed CONTROL+fibres and 4MK.4SF+fibres. 
Table 1. Proportioning of UHPC mixes

\begin{tabular}{|c|c|c|c|c|c|c|c|c|c|c|}
\hline Material & Units & $\begin{array}{c}\text { CONTR } \\
\text { OL }\end{array}$ & 8MK & $\begin{array}{c}\text { 10M } \\
\mathrm{K}\end{array}$ & $\begin{array}{c}10 \mathrm{M} \\
\mathrm{K} \\
+2 \mathrm{~N} \\
\mathrm{~S}_{1} \\
\end{array}$ & $8 S F$ & $\begin{array}{c}\text { 4MK.4S } \\
\text { F }\end{array}$ & $\begin{array}{c}4 \mathrm{MK} .4 \mathrm{~S} \\
\mathrm{~F} \\
+2 \mathrm{NS}_{1}\end{array}$ & $\begin{array}{c}\text { 4MK.4S } \\
\text { F } \\
+1.5 \mathrm{NS}_{1}\end{array}$ & $\begin{array}{c}4 \mathrm{MK} .4 \mathrm{SF} \\
+2 \mathrm{NS}_{1-2}\end{array}$ \\
\hline Cement & {$\left[\mathrm{kg} / \mathrm{m}^{3}\right]$} & 1100.0 & $\begin{array}{c}1012 . \\
0\end{array}$ & 990.0 & 968.0 & $\begin{array}{c}1012 . \\
0\end{array}$ & 1012.0 & 990.0 & 995.5 & 990.0 \\
\hline Silica fume (SF) & {$\left[\mathrm{kg} / \mathrm{m}^{3}\right]$} & 0 & 0 & 0 & 0 & 88.0 & 44.0 & 44.0 & 44.0 & 44.0 \\
\hline Metakaolin (MK) & {$\left[\mathrm{kg} / \mathrm{m}^{3}\right]$} & 0 & 88.0 & 110.0 & 110.0 & 0 & 44.0 & 44.0 & 44.0 & 44.0 \\
\hline Nanosilica OX-50 (NS 1$)$ & {$\left[\mathrm{kg} / \mathrm{m}^{3}\right]$} & 0 & 0 & 0 & 22.0 & 0 & 0 & 22.0 & 16.5 & 16.5 \\
\hline Nanosilica AE-200 (NS2) & {$\left[\mathrm{kg} / \mathrm{m}^{3}\right]$} & 0 & 0 & 0 & 0 & 0 & 0 & 0 & 0 & 5.5 \\
\hline Water & {$\left[\mathrm{kg} / \mathrm{m}^{3}\right]$} & 220.0 & 220.0 & 220.0 & 220.0 & 220.0 & 220.0 & 220.0 & 220.0 & 220.0 \\
\hline Silica sand & {$\left[\mathrm{kg} / \mathrm{m}^{3}\right]$} & 1211.0 & $\begin{array}{c}1211 . \\
0\end{array}$ & $\begin{array}{c}1211 . \\
0\end{array}$ & $\begin{array}{c}1211 . \\
0\end{array}$ & $\begin{array}{c}1211 . \\
0\end{array}$ & 1211.0 & 1211.0 & 1211.0 & 1211.0 \\
\hline Superplastizicer (SP) & {$\left[\mathrm{kg} / \mathrm{m}^{3}\right]$} & 17.6 & 26.4 & 26.4 & 33.0 & 25.3 & 23.1 & 27.5 & 26.4 & 30.8 \\
\hline (\% of cement+additions) & & $1.6 \%$ & $2.4 \%$ & $2.4 \%$ & $3.0 \%$ & $2.3 \%$ & $2.1 \%$ & $2.5 \%$ & $2.4 \%$ & $2.8 \%$ \\
\hline Total & {$\left[\mathrm{kg} / \mathrm{m}^{3}\right]$} & 2548.6 & $\begin{array}{c}2557 . \\
4\end{array}$ & $\begin{array}{c}2557 . \\
4\end{array}$ & $\begin{array}{c}2564 . \\
0\end{array}$ & $\begin{array}{c}2556 . \\
3\end{array}$ & 2554.1 & 2558.5 & 2557.4 & 2561.8 \\
\hline $\mathrm{V}_{\text {paste }} / \mathrm{V}_{\text {aggregate }}$ & & 1.28 & 1.32 & 1.32 & 1.33 & 1.33 & 1.32 & 1.33 & 1.32 & 1.33 \\
\hline Spread diameter & {$[\mathrm{mm}]$} & 250 & 250 & 250 & 250 & 250 & 250 & 250 & 250 & 250 \\
\hline
\end{tabular}

UHPC and UHPFRC mixtures were prepared using a two-speed automatic laboratory mixer following the procedure shown in Table 2.

Table 2. Mixing sequence.

\begin{tabular}{cc}
\hline Steps & Time (s) \\
\hline 1. Addition of $75 \%$ of water and all the cementitious materials. & - \\
2. Low speed mixing. & 30 \\
3. Low speed mixing while sand is added. & 30 \\
4. High speed mixing. & 30 \\
5. Resting time. Addition of 25\% of water + SP (20s before the & 90 \\
end of this period) & 60 \\
\hline
\end{tabular}

It is worth noting that when supplementary cementitious materials were used they were mixed with the cement until reaching an homogeneous compound before starting mixing. In the case of the mixes where fibres were added, they were incorporated in the fifth step. Once mixed, the fresh materials were poured into metal moulds in two layers of equal thickness, which were compacted after each pour with 120 strokes. Each mould allows obtaining three prismatic specimens of dimensions 160mm-40mm-40mm (length-width-height, respectively). The specimens were removed from the moulds after 24 hours and kept in a climatic chamber $\left(20^{\circ} \mathrm{C}\right.$ of temperature and at least $95 \%$ of humidity) until the test age.

\section{Experimental campaign}

\subsection{Fresh state}

The determination of the consistency of the fresh UHPC was assessed, prior to the filling of the moulds, by means of the shaking table following the recommendation EN 1015-3 [19]. It should be mentioned that in order to achieve similar fresh properties the superplasticiser ranged from being $1.6 \%$ of the cementitious materials weight in the CONTROL mix up to $3 \%$ in the $10 \mathrm{MK}+2 \mathrm{NS}{ }_{1}$ 
formulation. Consequently, the slump flow of all mixes was 250mm approximately. In Figure 2 an image of the mini-cone being filled and of the patty of one of the mixes can be seen.
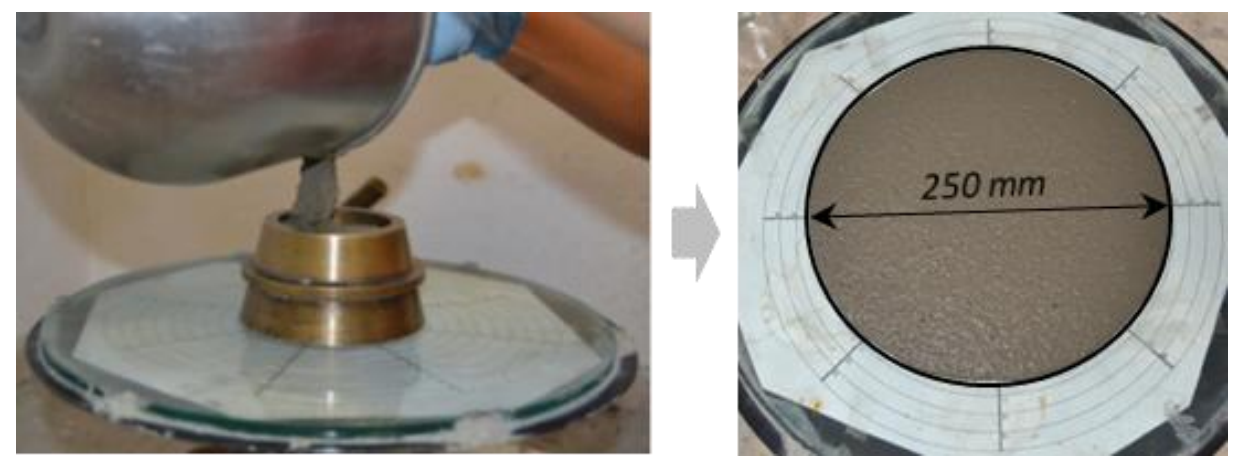

Figure 2. Determination of the consistency of fresh UHPC by shaking table. Spread diameter.

\subsection{Compressive strength test}

The compressive strength of the mixes was assessed following EN 1015-11 [20] at 2, 7 and 28 days of age. In the case of CONTROL+fibres and 4MK.4SF+fibres mixes tests were only conducted at 7 and 28 days of age. Prior to the compressive strength test, the specimens were tested using a three point bending setup and the resulting halves were employed in the compressive strength tests performed. An Ibertest hydraulic press, equipped with a load cell with a maximum capacity of 3,000 $\mathrm{kN}$, was used. The compressive strength tests were carried out by using a device that assured that the load exerted by the machine was applied on two metal plates of dimensions $40 \times 40 \mathrm{~mm}^{2}$. As established in [20] the load rate was fixed at $2.4 \mathrm{kN} / \mathrm{s}$. The testing machine, the loading device and the outlook of one of the samples with and without fibres after being tested can be seen in Figure 4.

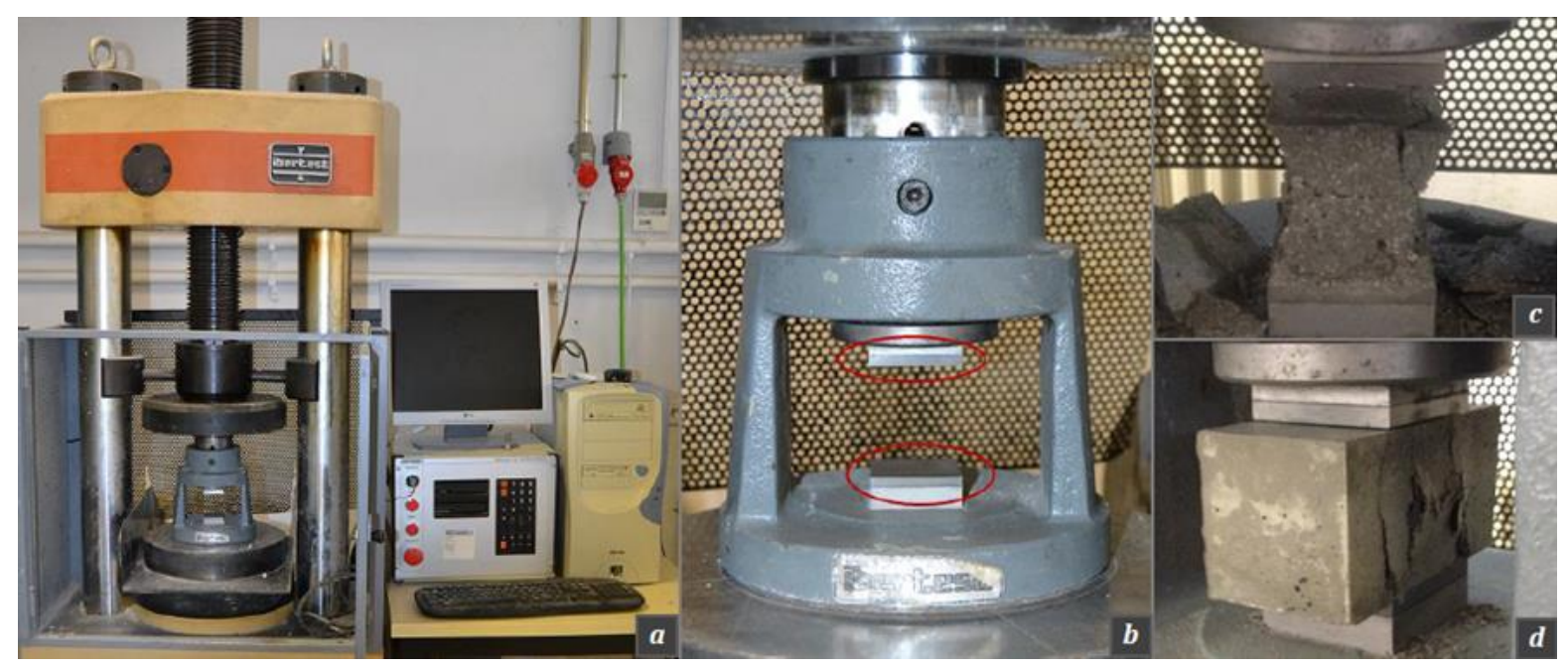

Figure 3. Compressive strength test: a) hydraulic press, b) device with steel supports of $40 \mathrm{~mm} \times 40 \mathrm{~mm}$, c) test specimen fracture without fibres, $d$ ) test specimen fracture with fibres.

\subsection{Microstructural characterization}

In order to relate the compressive strength tests with the microstructure of the tested matrixes, differential thermal and thermogravimetric analysis (DTA-TG) and mercury intrusion porosimetry (MIP) tests were carried out at 28 days of age in the mixtures that did not include metallic fibres. At least two samples of each formulation were analysed in each test.

MIP test was carried out in cylindric samples extracted from undamaged samples by using a water-cooled column drill. The cylindrical specimens were placed for half an hour in a vacuum pump 
to extract the water present in the pores. They were then immersed in isopropanol for 24 hours and dried in an oven at $40^{\circ} \mathrm{C}$ until the time of the test. The cement hydration was stopped following the described procedure. The MIP analysis was performed on a Micromeritics Autopore IV 9500 equipment, operating up to a pressure of $33000 \mathrm{psi}(228 \mathrm{MPa})$ and covering a pore diameter range from 0.006 to $175 \mu \mathrm{m}$. Penetrometers of $5 \mathrm{~cm}^{3}$ of bulb and $0.366 \mathrm{~cm}^{3}$ of stem were used. The equipment used can be seen Figure 5.b.

In the case of the DTA-TG tests, the samples followed the same procedure as in the case of the MIP tests. Afterwards, they were manually grinded before using an automatic Retch RM200 mortar grinder which reduced the size of the particles up to a point where the maximum particle was smaller than $0.5 \mathrm{~mm}$. The dust obtained was stored in sealed plastic bags until the tests were performed. The DTA-TG tests were performed following an adaptation of ASTM E1131: 2008 [21] in a N2 environment using a simultaneous thermal analyser Setaram brand, model Labsys Evo, provided with a $0.1 \mathrm{mg}$ precise balance. The procedure used a $10^{\circ} \mathrm{C} / \mathrm{min}$ heating ramp between $40^{\circ} \mathrm{C}$ and $1,100^{\circ} \mathrm{C}$ and the crucibles used were made of alumina $\left(\alpha-\mathrm{Al}_{2} \mathrm{O}_{3}\right)$ previously calcined at $1,500^{\circ} \mathrm{C}$ which was employed as reference material. The equipment used can be seen Figure 5.a.

The electrical resistivity test, which has the advantage of being a non-destructive test, was carried out according to UNE 83988-1 [22], using the Giatec RCON ${ }^{\mathrm{TM}}$ measuring equipment, capable of measuring the electrical resistance $\left(R_{e}\right)$ of concrete specimens using a uniaxial method within a frequency range of $1 \mathrm{~Hz}-30 \mathrm{kHz}$. The equipment applies a uniform electric field by means of two electrodes that contact the bases of the saturated concrete specimen through sponges previously moistened and saturated with gel. For each type of concrete, the average value of two measurements made at 28 days of curing was considered. Then, the electrical resistivity $\left(\rho_{e}\right)$ was calculated according to the following equation:

$$
\rho_{e}=R_{e} k=R_{e} \frac{S}{L}
$$

Where $\rho_{e}$ is the electrical resistivity $(\Omega \mathrm{m}), k$ is the cell constant $(\mathrm{m}), R_{e}$ is the electrical resistance $(\Omega), S$ is the surface area of the specimen in contact with sponges $\left(\mathrm{m}^{2}\right)$ and $L$ is the height of the specimen.

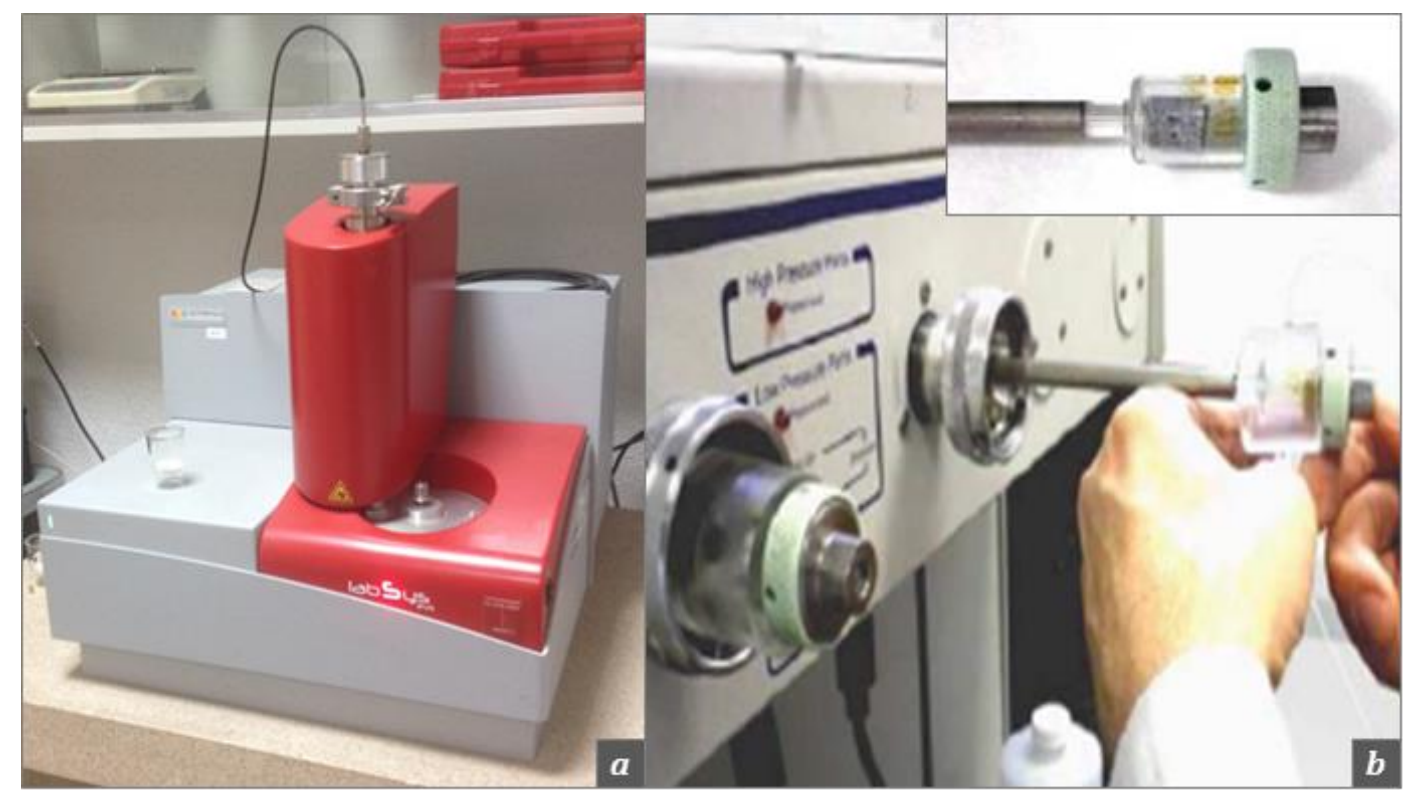

Figure 4. a) Simultaneous thermal analyser used for TDTA-TG tests. b) Equipment used for MIP tests and penetrometer detail with cylindrical sample inside. 


\section{Experimental results}

\subsection{Compressive strength}

Table 4 shows the compressive tests results for all the mixes performed at 2, 7 and 28 days of age. Having the compressive strength values at different ages permitted not only comparing the strength of the mixes but also to assess the effect of the combination of nano additions and additions in the evolution of strength of the concrete mixes. In order to establish the possible experimental scattering the coefficient of variation was also included.

Table 3. Compressive strength values of UHPC studied at different ages.

\begin{tabular}{|c|c|c|c|c|c|c|c|c|c|c|c|c|c|c|c|c|c|}
\hline $\begin{array}{c}\text { Compressive } \\
\text { Strength }\end{array}$ & $\mathrm{COI}$ & ROL & $8 S F$ & $8 \mathrm{MK}$ & $4 \mathrm{MK}$ & $.4 S F$ & $10 \mathrm{MK}$ & $\begin{array}{l}10 \mathrm{MK} \\
+2 \mathrm{NS}_{1}\end{array}$ & $\begin{array}{r}4 \mathrm{MK} \\
+1.5 \\
\end{array}$ & $\begin{array}{l}.4 S F \\
\mathrm{NS}_{1}\end{array}$ & $\begin{array}{r}4 \mathrm{MK} \\
+2 \mathrm{I} \\
\end{array}$ & $\begin{array}{l}.4 S \mathrm{SF} \\
\mathrm{JS1}\end{array}$ & $\begin{array}{r}4 \mathrm{MK} \\
+2 \mathrm{~N} \\
\end{array}$ & $\begin{array}{l}4 S F \\
\text { JSc }\end{array}$ & $\begin{array}{l}\text { CTRL } \\
+ \text { fibres }\end{array}$ & $\begin{array}{r}4 \mathrm{MK} \\
+\mathrm{fib}\end{array}$ & $\begin{array}{l}.4 S F \\
\text { res }\end{array}$ \\
\hline$f_{c k, 2 d}[\mathrm{MPa}](\% \mathrm{CV})$ & 102 & (2.9) & $101_{(4.9)}$ & $103_{(0.5)}$ & 106 & $(0.4)$ & $96(2,5)$ & $98 \quad(1,9)$ & 105 & $(2,6)$ & 101 & $(4,6)$ & 105 & $(0,5)$ & - & & \\
\hline$f_{c k, 7 d}[\mathrm{MPa}](\% \mathrm{CV})$ & 112 & (1.1) & $119_{(0.6)}$ & 117 & 122 & (7.6) & $113_{(2,1)}$ & $118_{(3,0)}$ & 120 & $(0,8)$ & 116 & $(6,7)$ & 126 & $(3,6)$ & 135 (1.9) & 146 & (1.7) \\
\hline$f_{c k, 28 d}[\mathrm{MPa}](\% \mathrm{CV})$ & 124 & (2.8) & $138_{(1.8)}$ & $136_{(4.1)}$ & 140 & (5.3) & $133_{(3,0)}$ & $136_{(2,2)}$ & 141 & $(2,5)$ & 144 & $(2,2)$ & 140 & $(2,3)$ & $153_{(2.0)}$ & 171 & (2. \\
\hline
\end{tabular}

In Table 4 it can be clearly perceived that the high amount of cement together with the reduced water to cement ratio generated a remarkable compressive strength in the CONTROL formulation. It should be underlined that even at two days of age the compressive strength of the mentioned mix surpassed 100MPa. Between two and 28 days of age the compressive strength increased almost a $25 \%$ being the development of strength more relevant in the first week. In the case of the $8 \mathrm{MK} \mathrm{mix}$, at two days the compressive strength was above also 100MPa. Moreover, the increment of strength between two and 28 days was close to a $40 \%$. Similarly as in the case of the CONTROL mix the compressive strength evolution was evident in the first week of age but at 28 days there was a greater increment if such value is compared with the one at two days. The compressive strength of the $10 \mathrm{MK}$ mix was slightly below 100MPa at two days of age. Although a noticeable increment of resistance was noticed during the first week of age of the samples, the enhancement of mechanical properties was greater between seven and 28 days. In fact, $10 \mathrm{MK}$ mix virtually reached the same strength than the $8 \mathrm{MK}$ mix at 28 days even though the initial values registered were smaller. A similar trend can be detected when analysing the results of the $10 \mathrm{MK}+2 \mathrm{NS} \mathrm{S}_{1}$ mix. It was registered a two-day strength below 100 MPa followed by a rising of the resistance as time passed until 135MPa were reached at 28 days of age. No improvement of the compressive strength was detected when $\mathrm{NS}_{1}$ was combined MK. The evolution of resistance of the $8 \mathrm{SF}$ mix is quite similar to the one detected in the $8 \mathrm{MK}$ mix. In the case of the $4 \mathrm{MK} 4 \mathrm{SF}$ formulation, the initial compressive strength was above $100 \mathrm{MPa}$, being the greatest of all the mixes tested. Such strength evolved up to values close to the ones of the previously commented mixes not being the highest at 28 days of age. When $2 \%$ of $\mathrm{NS}_{1}$ was added to $4 \%$ of MK and $4 \%$ of SF a remarkable improvement of the strength could be noticed between seven and 28 days of age reaching over $140 \mathrm{MPa}$. It is curious that if $\mathrm{NS}_{1}$ is reduced to $1.5 \%$ the compressive strength of the material is almost stable being close to the highest value registered ( $4 \mathrm{MK} 4 \mathrm{SF}+1.5 \mathrm{NS} \mathrm{S}_{1}$ mix). Lastly, $4 \mathrm{MK} 4 \mathrm{SF}+2 \mathrm{NS}_{1-2}$ shows similar trends that the ones perceive for most of the mixes can be seen.

In contrast to the homogeneity of the compressive strength values previously commented, the mixes where the steel fibres were added showed a notable increment of compressive strength between seven and 28 days of age. Besides, it should be underlined that the $4 \mathrm{MK} 4 \mathrm{SF}+\mathrm{fibres}$ mix reached 171MPa of compressive strength at 28 days of age. There is not a complete assessment of the strength evolution in these mixes due to the absence of test results at two days of age. In any case it should be highlighted that in all test and at all ages the experimental scatter was remarkably low due to the careful manufacturing, curing and testing that was carried out.

Figure 6 shows the comparison of the compressive strength of the mixes considering that the CONTROL mix strength is 1 . In such figure, it can be perceived that all the mixes where a certain proportion of cement was substituted by a pozzolanic addition showed a greater compressive strength. The increment of the compressive strength of the mixes if compared with CONTROL were 
between an eight and a $14 \%$ at 28 days of age. However, it should be also mentioned that the differences that appear among the mixes with additions and without fibres are scarce and lay within the coefficient of variation values. This aspect is valid independently of the age of the mix. Based on the previous comments, it might be stated that there are no clear influence of the additions and their combinations in the compressive strength of the mixes analysed. On the contrary, when steel fibres are added to the CONTROL (CONTROL+fibres) and the 4MK4SF (4MK4SF+fibres) mixes the presence of fibres clearly improved the behaviour of the correspondent mixes reaching up to $30.4 \%$ and $36.8 \%$ increment at 7 and 28 days respectively, compared with the control mixture without fibres.

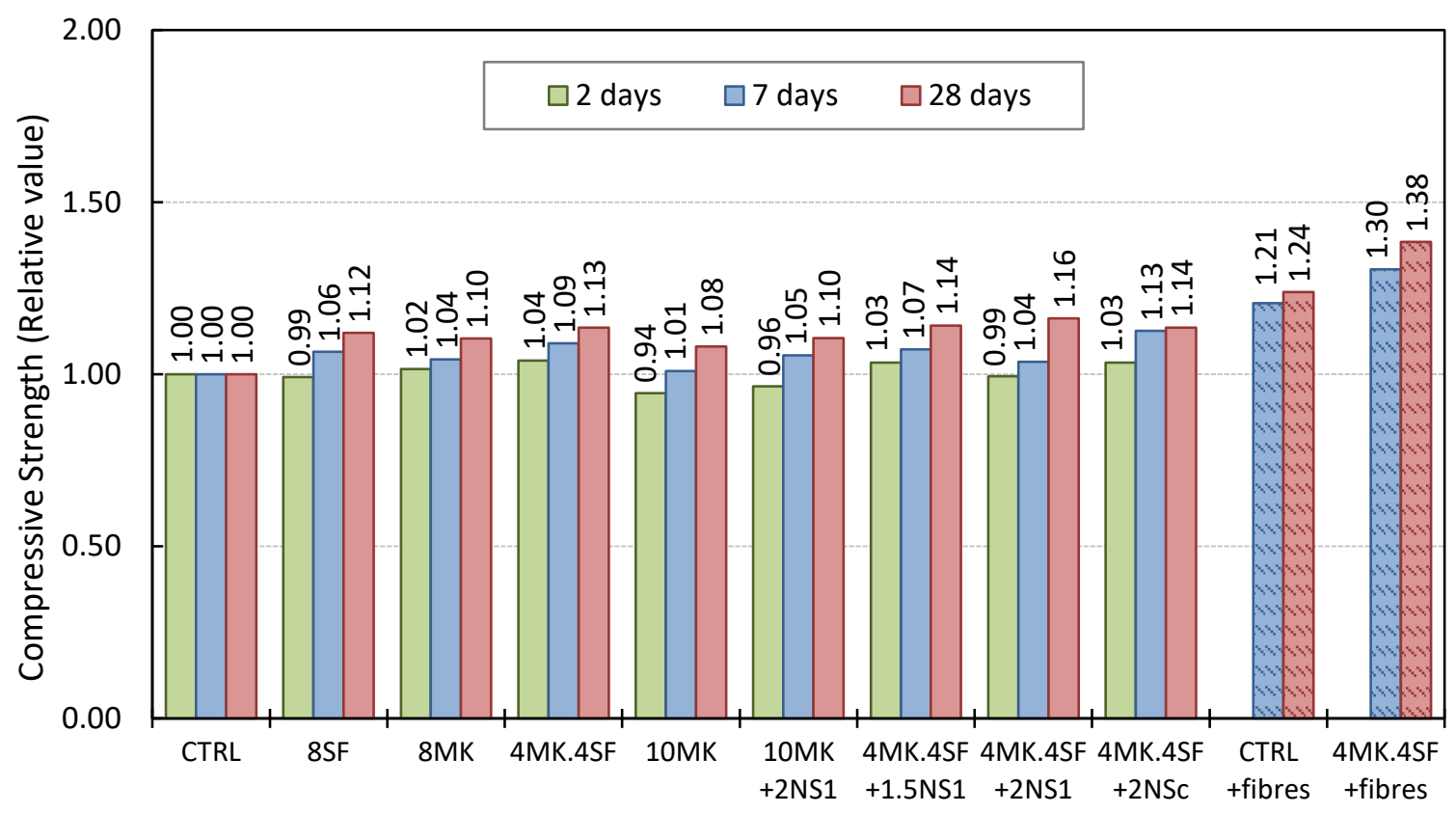

Figure 5. Relative increment of strength. CONTROL mix results are taken as the unity at two, seven and 28 days of age for reference.

\subsection{Mercury intrusion porosimetry (MIP)}

The results of the MIP test can be seen in Figure 7. It should be mentioned that MIP tests were only carried out in the mixes without fibres. While in Figure 7a appear the results of the logarithm of differential intrusion versus the pore size, in Figure $7 \mathrm{~b}$ appear the cumulative intrusion versus the pore size. The first characteristic that can be perceive in Figure $7 \mathrm{a}$ is that CONTROL boasts a noticeable higher pore critical diameter if compared with the mixes where additions were used. Moreover, the area below the curve of the CONTROL mix is remarkably greater than in the rest of the cases. If a more detailed analysis of the test results is performed, it can be clearly seen that the mixes that combined a $4 \%$ of MK a $4 \%$ of SF and a certain content of nano additions boasted a reduced size of the pore critical diameter. Moreover, the area below such curves were also noticeable smaller that the correspondent of the rest of mixes. Analysing such curves and comparing them with the one of CONTROL it could be clearly seen that the pore critical diameter has clearly shifted towards the left, which means a smaller size of the pore critical diameter. A similar, but at the same time more subtle effect, can be seen if the CONTROL curve is compared to the ones of the mixes were traditional additions (MK and SF), or even combination of them were employed. In such cases, it is the reduction of the size of the pore critical diameter less evident. Similarly, the area below the curves is smaller than in the case of CONTROL but at the same time greater than the one of the mixes that included a combination of $4 \% \mathrm{MK}, 4 \% \mathrm{SF}$ and a certain content of nano additions. It should be also highlighted that the critical pore size of the mixes where only MK was used boasted a greater pore critical diameter than those where SF were employed. 
If the cumulative intrusion registered in the tested mixes is compared, it can be clearly seen that similar trends to the ones previously commented appear. The CONTROL formulation registers the greatest intrusion of mercury. On the contrary the mixes $4 \mathrm{MK} 4 \mathrm{SF}+1.5 \mathrm{NS} 1,4 \mathrm{MK} 4 \mathrm{SF}+2 \mathrm{NS}{ }_{1}$ and $4 \mathrm{MK} 4 \mathrm{SF}+2 \mathrm{NS}_{1-2}$ not only were the ones where a more limited amount of mercury was intruded, but also boasted the smallest pore threshold diameter. The results in these three formulations were remarkably similar. The mixes were MK and SF were used showed a smaller amount of mercury intruded if compared with the CONTROL mix. However, if the effect of both additions is compared it can be seen that SF was not equally effective to MK. The use of SF generates a greater reduction of the amount of intruded mercury than MK. Oppositely, there seems to have no remarkable differences in the pore threshold diameter of the mixes independently of the use of SF or MK.
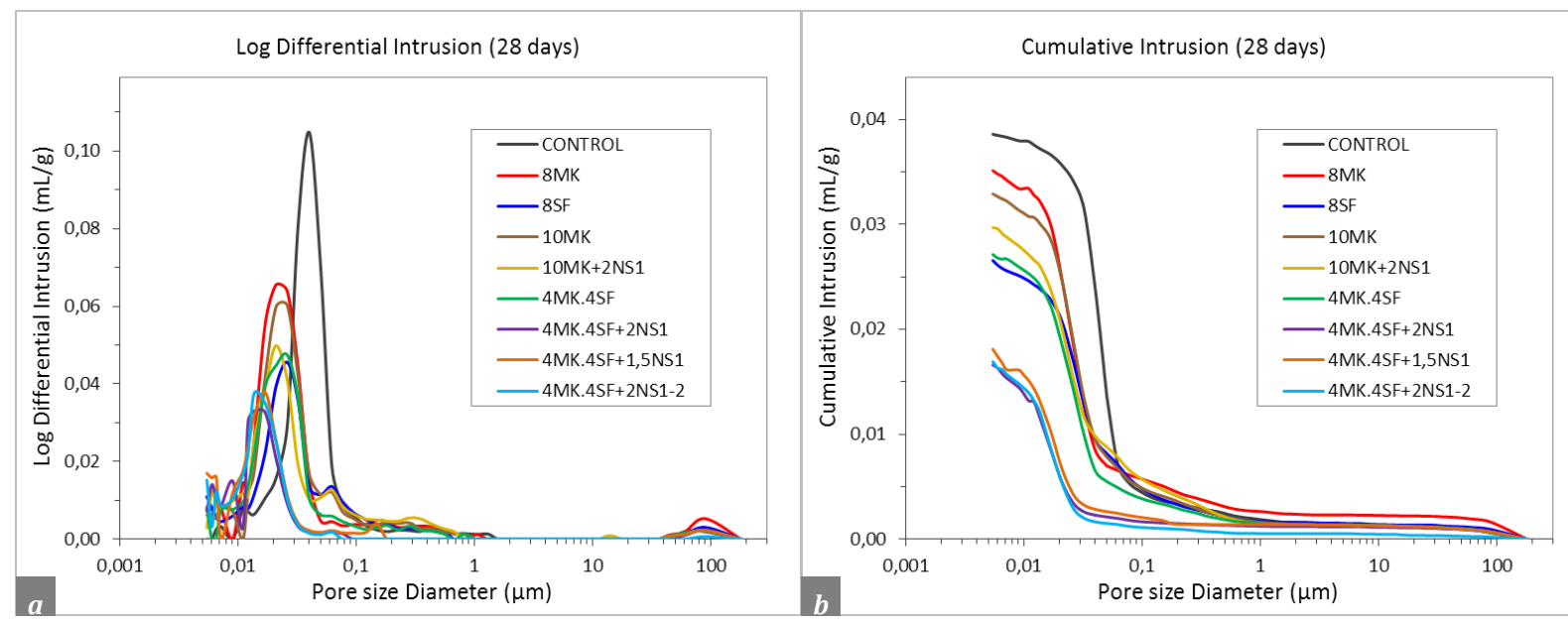

Figure 6. Graphs of MIP tests at 28 days. a) Logarithm differential of mercury intrusion. b)

Cumulative intrusion volume.

If the values of total porosity, median pore diameter, threshold diameter, total intrusion volume and tortuosity are extracted from the test results, Table 5 can be performed. In this table it can be seen that the presence of nano additions, when combined with $4 \%$ of $\mathrm{MK}$ and $4 \%$ of SF, reduced more than $50 \%$ the porosity of the mixes. It is also true that SF and MK by themselves are capable of lessening the porosity, but it cannot be overlooked that such reductions are approximately half of the ones obtained with nano additions. Regarding the variation of the pore threshold diameter, it could be said that when SF and MK are added independently there is no clear trend. In what the median pore diameter in concern, the use of nano additions reduce its size more than $50 \%$ while the use of traditional additions only reaches reductions around $25 \%$.

Table 4. Parameters of the mercury intrusion porosimetry tests at 28 days.

\begin{tabular}{|c|c|c|c|c|c|c|c|c|c|c|}
\hline Parameters & Units & CTRL & $8 \mathrm{MK}$ & $8 \mathrm{SF}$ & $10 \mathrm{MK}$ & $\begin{array}{l}10 \mathrm{MK} \\
+2 \mathrm{NS}_{1} \\
\end{array}$ & 4MK.4SF & $\begin{array}{c}\text { 4MK.4SF } \\
+2 \mathrm{NS}_{1}\end{array}$ & $\begin{array}{r}4 \mathrm{MK} .4 \mathrm{SF} \\
+1,5 \mathrm{NS} 1 \\
\end{array}$ & $\begin{array}{c}4 \mathrm{MK} .4 \mathrm{SF} \\
+2 \mathrm{NS}_{1-2} \\
\end{array}$ \\
\hline $\begin{array}{c}\text { Total Intrusion } \\
\text { Volume }\end{array}$ & {$[\mathrm{mL} / \mathrm{g}]$} & 0.0386 & 0.0351 & 0.0265 & 0.0329 & 0.0297 & 0.0271 & 0.0166 & 0.0181 & 0.0169 \\
\hline $\begin{array}{c}\text { Median Pore } \\
\text { Diameter }\end{array}$ & {$[\eta \mathrm{m}]$} & 44.3 & 27.1 & 31.6 & 28.7 & 26.9 & 27.1 & 17.2 & 18.2 & 17.2 \\
\hline Threshold Diameter & {$[\eta \mathrm{m}]$} & 95.3 & 50.4 & 120.8 & 77.1 & 120.9 & 62.5 & 32.4 & 40.3 & 40.3 \\
\hline Porosity & {$[\%]$} & 8.99 & 7.98 & 6.13 & 7.51 & 6.76 & 6.26 & 3.87 & 4.21 & 3.96 \\
\hline Tortuosity & & 4.45 & 4.56 & 4.58 & 4.21 & 10.37 & 4.23 & 4.50 & 4.33 & 3.67 \\
\hline
\end{tabular}




\subsection{Differal thermal and thermogravimetric analysis (DTA-TG)}

In addition, the mixes were analyzed by Differential Thermal Analysis (TGA/DTA). TGA/DTA profiles, according to ASTM E 1131 [21]. Plotting the derivative of the weight loss or what is the same the speed of weight loss (dTG) vs. temperature is more useful than the representation of the weight loss (TG) vs. temperature as it allows, in a way, a more clear and unequivocal identification of the different start and end temperatures of different processes of weight loss with temperature. From the temperatures selected for the representation of dTG vs. TG, the quantification of the weight loss with the temperature associated with the different reactions that occur in the cement was carried out. Figure 8 shows the dTG vs. temperature of the mixes. Based on the methods proposed by Bhatty [23], Pane et al. [24] and Monteagudo et al. [25], various regions of dehydration, Ldh (region $T_{1}$ ), dehydroxylation, $\operatorname{Ldx}\left(\right.$ region $T_{2}$ ) and decarbonation, Ldc (region $T_{3}$ ), are highlighted in Figure 8.

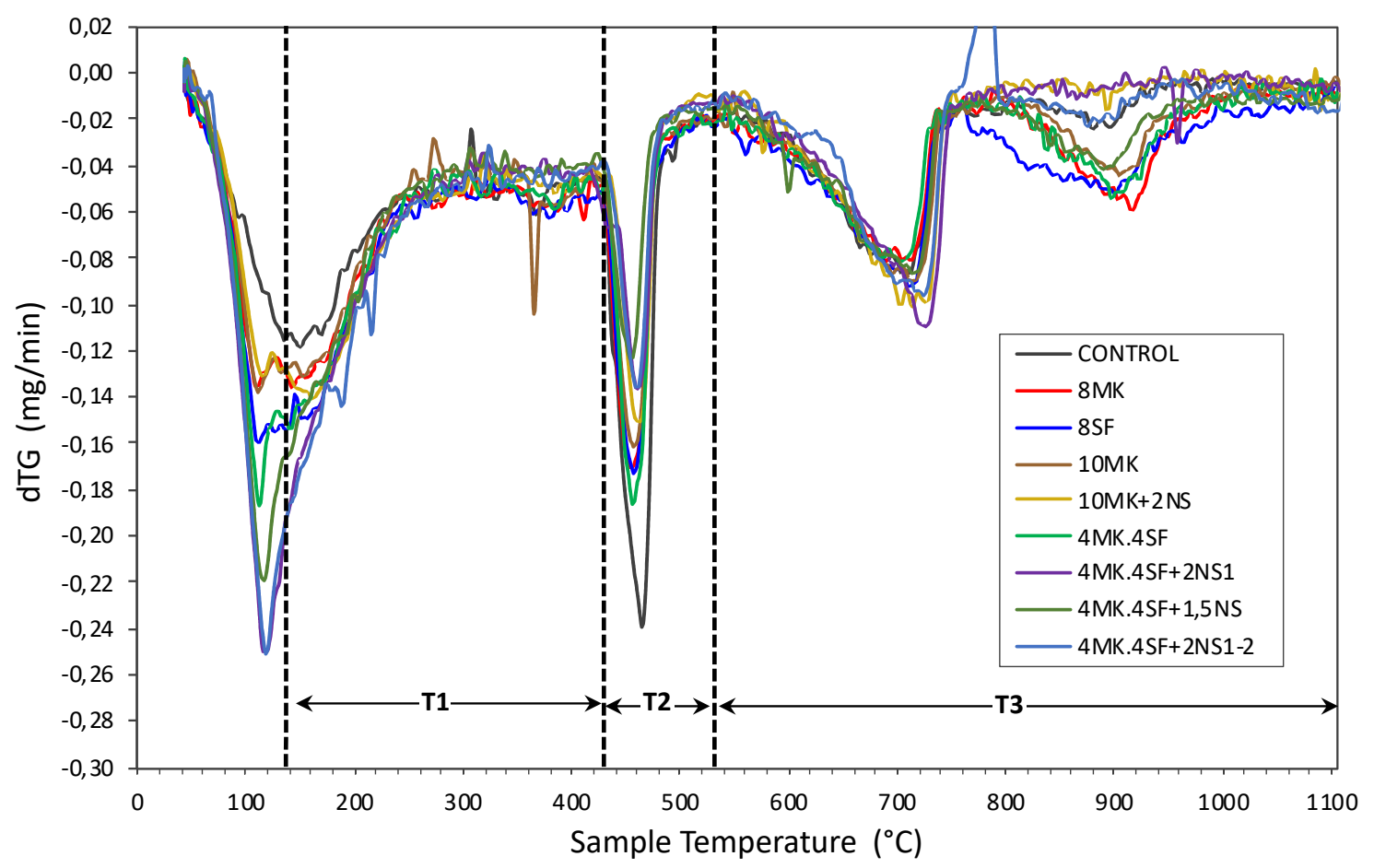

Figure 7. Curves of the thermogravimetric derivative according to temperature ranges.

Table 6 shows the Portlandite, C-S-H gel and Portlandite $(\mathrm{CH})$ contents based on the TG results at the age of 28 days for all the mixtures. The key values for comparison the influence of the additions and nanoadditions in the cement hydration are the ratio water of C-S-H gel/cement content and the equivalent calcium content.

The ratio water of C-S-H gel/cement increases when the cement additions are incorporated to the mixes, being the highest values shown by the mixtures $10 \mathrm{MK}+2 \mathrm{NS} 1$ and $4 \mathrm{MK} .4 \mathrm{SF}+1.5 \mathrm{NS} 1$, both including nano silica. In addition, the value of the $\mathrm{CH}$ is the lowest for both mixtures. This is consistent with the high degree of hydration that nano silica usually produces at the age of 28 days. The rest of mixtures show lower hydration values compared with to those shown 10MK+2NS1 and $4 \mathrm{MK} .4 \mathrm{SF}+1.5 \mathrm{NS1}$. The lowest value of the ratio water of C-S-H gel/cement content is shown by the CONTROL mixture. 
Table 6. Percentage of water loss according to temperature ranges at 28 days.

\begin{tabular}{|c|c|c|c|c|c|c|c|c|c|c|}
\hline Parameters & Units & CONTROL & $8 S F$ & $8 \mathrm{MK}$ & 4MK.4SF & $10 \mathrm{MK}$ & $\begin{array}{l}10 \mathrm{MK} \\
+2 \mathrm{NS} 1\end{array}$ & $\begin{array}{l}4 \mathrm{MK} .4 \mathrm{SF} \\
+1,5 \mathrm{NS} 1\end{array}$ & $\begin{array}{c}4 \mathrm{MK} .4 \mathrm{SF} \\
+2 \mathrm{NS} 1\end{array}$ & $\begin{array}{l}4 \mathrm{MK} .4 \mathrm{SF} \\
+2 \mathrm{NS}_{1-2}\end{array}$ \\
\hline $\mathrm{T}_{1}\left(140-430{ }^{\circ} \mathrm{C}\right)$ & {$[\%]$} & 6.43 & 7.85 & 7.28 & 7.56 & 6.81 & 7.35 & 7.97 & 8.02 & 8.04 \\
\hline $\mathrm{T}_{2}\left(430-530^{\circ} \mathrm{C}\right)$ & {$[\%]$} & 2.94 & 2.26 & 2.27 & 2.25 & 2.04 & 1.79 & 1.60 & 1.74 & 1.82 \\
\hline $\mathrm{T}_{3}\left(530-1105^{\circ} \mathrm{C}\right)$ & {$[\%]$} & 4.39 & 6.57 & 5.65 & 5.39 & 5.11 & 4.16 & 5.16 & 7.29 & 6.18 \\
\hline $\begin{array}{l}\text { Total combined } \\
\text { water } \\
\left(\mathrm{T} 1+\mathrm{T} 2+0,41^{*} \mathrm{~T} 3\right)\end{array}$ & {$[\%]$} & 11.17 & 12.80 & 11.87 & 12.02 & 10.94 & 10.85 & 11.68 & 12.75 & 12.39 \\
\hline $\begin{array}{c}\text { Equivalent } \\
\text { calcium }(\mathbf{C H}) \\
\left(\mathrm{T} 2+0,41^{*} \mathrm{~T} 3\right)\end{array}$ & {$[\%]$} & 4.74 & 4.96 & 4.58 & 4.46 & 4.13 & 3.49 & 3.71 & 4.73 & 4.35 \\
\hline $\begin{array}{c}\text { CSH gel / CH } \\
\mathrm{T} 1 /\left(\mathrm{T} 2+0,41^{*} \mathrm{~T} 3\right)\end{array}$ & & 1.36 & 1.58 & 1.59 & 1.69 & 1.65 & 2.11 & 2.15 & 1.70 & 1.85 \\
\hline
\end{tabular}

\subsection{Electrical resistivity}

The electrical resistivity in a saturated concrete is an indirect measure of the connectivity and the size of its pores. This volumetric property, according to Ohm's Law, relates the resistance of the material to the passage of electric charges with a geometric factor that is a function of the length and cross section of the specimen. These tests were carried out according to the UNE 83988-1 [22]. In table 7 it can be seen that all the mixes where additions were used registered resistivity values one order of magnitude higher than the control formulation. Moreover, if no nano additions are used, SF seem to be more apt for reducing the connected porosity than MK. In the cases where nanoadditions were employed it can be perceived a notable increment of the resistivity found. Also, no notable effects of $\mathrm{NS}_{2}$ were detected. It should be highlighted that the highest value of resistivity was found in the mix with the greatest substitution of cement by additions.

Table 5. Resistivity values of the main mixtures.

\begin{tabular}{|c|c|c|c|c|c|c|c|c|c|c|}
\hline Parameters & Units & CONTROL & $8 S F$ & $8 \mathrm{MK}$ & 10MK & $10 \mathrm{MK}$ & MK. & 4MK.4SF & 4MK.4SF & 4MK.4SF \\
\hline & & & & & & $+2 \mathrm{NS}_{1}$ & & $+2 \mathrm{NS}_{1}$ & $+1,5 \mathrm{NS}_{1}$ & $+2 \mathrm{NS}_{1-2}$ \\
\hline Resistivity & {$[\Omega . \mathrm{m}]$} & 184 & 2400 & 2150 & 2325 & 4170 & 2485 & 3830 & 3680 & 3610 \\
\hline
\end{tabular}

\section{Discussion}

Figure 8 shows the total porosity of the samples at 28 days, as well as the distribution of the pores according to their size, expressed as percentages of the total porosity. These graphs were elaborated from the cumulative mercury intrusion curves shown in Figure 6b, where the total porosity equivalent to $100 \%$ of the volume of mercury intrusion is shown. 


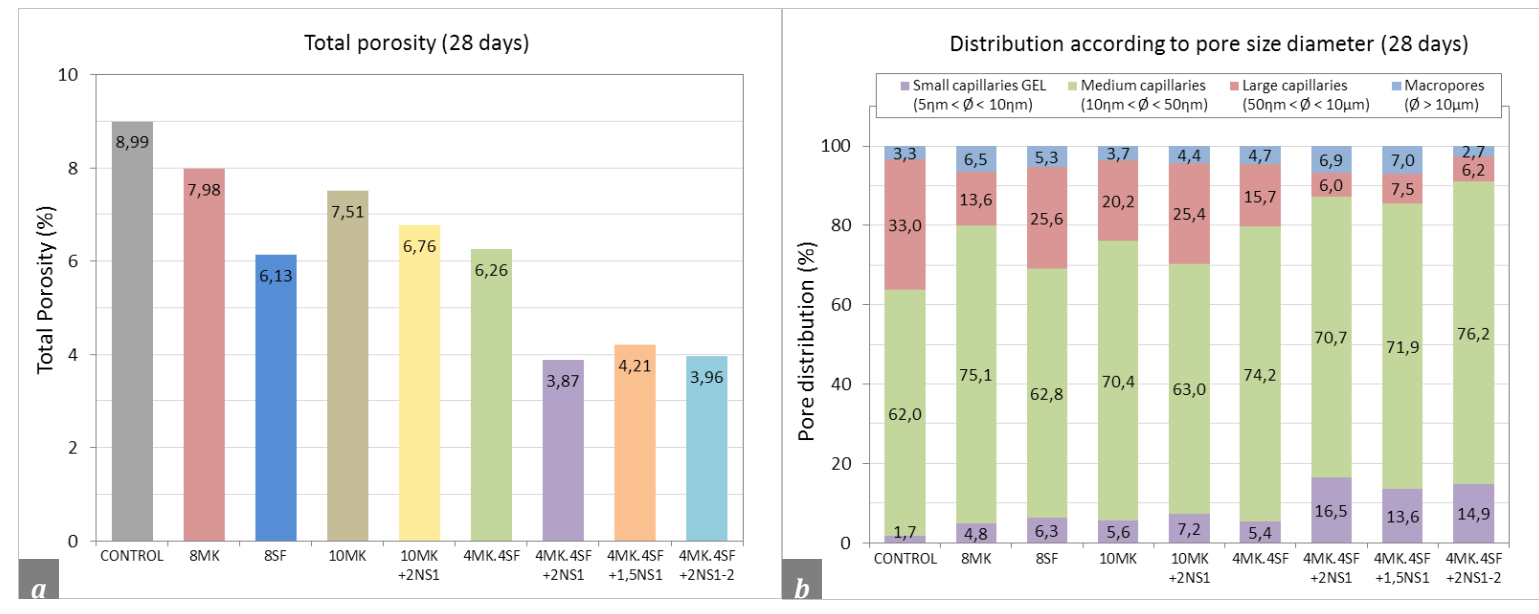

Figure 8. a) Total porosity at 28 days. b) Distribution of the porous network at 28 days.

As evidenced in Figure 8a, samples with additions reveal a lower total porosity at 28 days compared with the control sample, which already has a low porosity. A minimum porosity percentage of $3.87 \%$ was reached in the case of the $4 \mathrm{MK} .4 \mathrm{SF}+2 \mathrm{NS} 1$ sample, which represents a porosity reduction of $56 \%$. This increase in the density of the UHPC matrices is coherent with higher value of hydration shown by the ratio water of C-S-H gel/cement content and the equivalent calcium content in DTA-TG analysis. In particular, the highest values of the ratio water of C-S-H gel/cement content are reached by $4 \mathrm{MK} .4 \mathrm{SF}+1.5 \mathrm{NS} 1$ and $10 \mathrm{MK}+2 \mathrm{NS} 1$, which correspond with the lowest values of the total porosity. In addition, both mixtures show a high resistivity value and the best compressive strength (see Table 3 ).

The distribution of the porous network, which is presented in Figure $8 \mathrm{~b}$. It shows that in all cases the medium capillaries predominate, with diameters between $10 \eta \mathrm{m}$ and $50 \eta \mathrm{m}$. Large capillaries, with diameters between 50 and $100 \mu \mathrm{m}$, seem to decrease with the use of additions, while the percentage of small capillaries, with diameters between 5 and $10 \mu \mathrm{m}$, increases. The increase in the percentage of small capillaries is very evident with the use of nanosilica. Figure $8 \mathrm{~b}$ shows, for example, the mixtures $10 \mathrm{MK}$ and $10 \mathrm{MK}+2 \mathrm{NS}_{1}$, whose percentages of small capillaries are $5.6 \%$ and $7.2 \%$ respectively, which represents an increase of $28.6 \%$ when replacing $2 \%$ of the cement content with nanosilice OX-50. Similarly, the values of $4 \mathrm{MK} .4 \mathrm{SF}$ and $4 \mathrm{MK} .4 \mathrm{SF}+1.5 \mathrm{NS}_{1}$ can be observed, with percentages of small capillaries of $5.4 \%$ and $16.5 \%$ respectively, which represents an increase of $205.6 \%$ in the percentage of these capillaries when replacing $1.5 \%$ of the cement content per nanosilice OX-50. In both cases, the total porosity is also reduced, as shown in Figure 8a.

In addition, Figure 9 shows the relation between the ratio water of C-S-H gel/cement content and the compressive strength of the different specimens. 

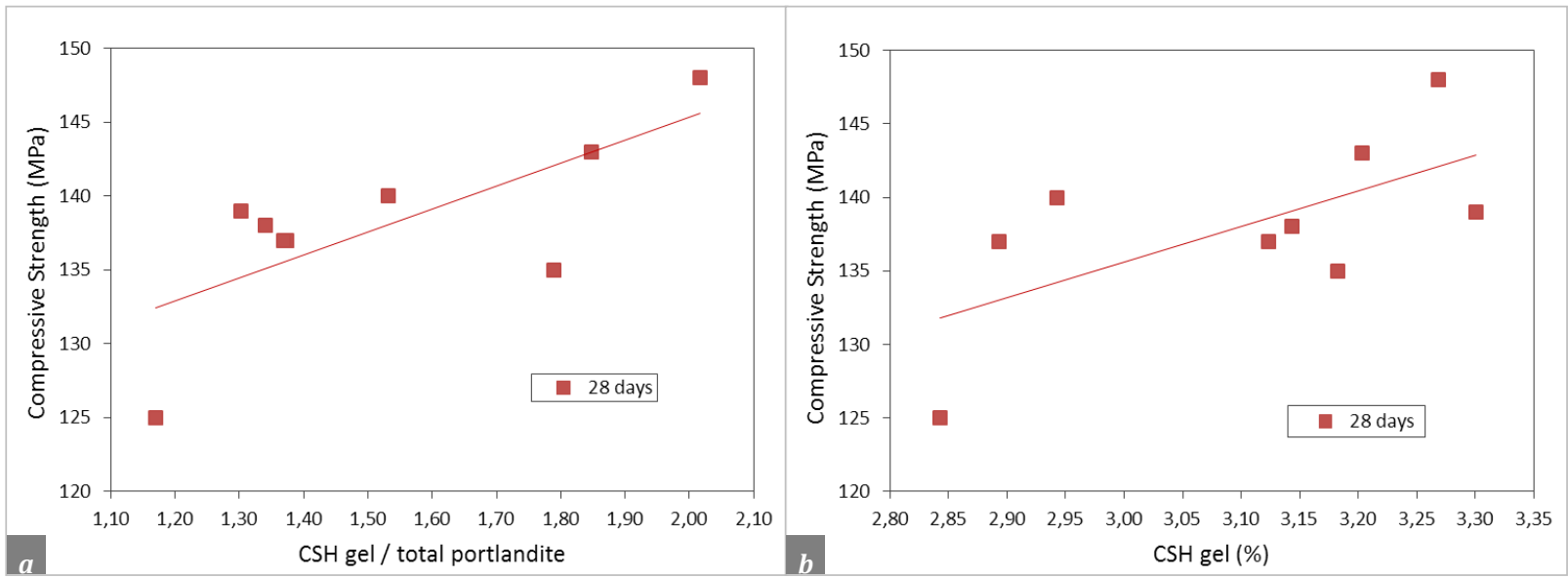

Figure 9. Influence of portlandite and CSH gel on compressive strength at 28 days.

The use of additions such as metakaolin and silica fume increase compressive strength significantly as shown in Table 3, in addition to reducing the total porosity and especially the large capillaries as seen in Figure 8. When nanosilica is added to the pozzolanic materials mentioned above, the compressive strength is not greatly affected, but in contrast the densification of the matrix and the corresponding reduction in porosity are significantly favored.

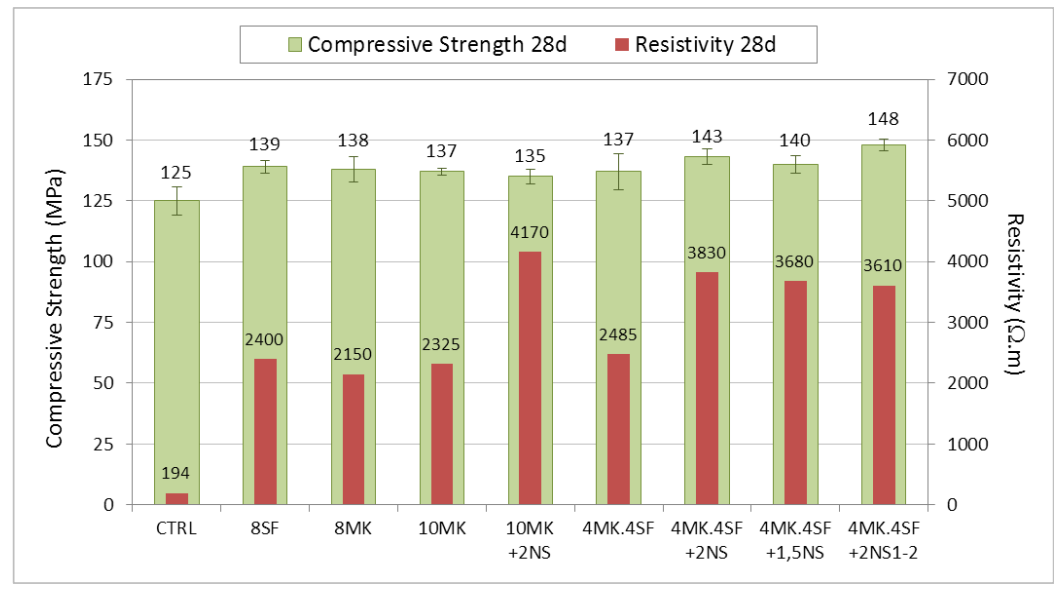

Figure 8. Influence of additions and nanoaditions on resistivity and compressive strength .

In Figure 11 it can be seen how the use of additions, especially nanosilica, is reflected in a very significant increase in resistivity compared with the control sample. For example, in the 10MK and $10 \mathrm{MK}+2 \mathrm{NS}_{1}$ mixtures, a slight decrease in the compressive strength is observed when $2 \%$ of the weight of the cement is substituted by nanosilice OX-50, while its resistivity practically doubles. In the case of mixtures containing $4 \%$ of metakaolin and $4 \%$ of silica fume, it can be seen how the use of nanosilica slightly increases the compressive strength in the mixtures $4 \mathrm{MK} .4 \mathrm{SF}+2 \mathrm{NS}_{1}$ and $4 \mathrm{MK} .4 \mathrm{SF}+1.5 \mathrm{NS}_{1}$, and in a higher grade in $4 \mathrm{MK} .4 \mathrm{SF}+2 \mathrm{NS}_{1-2}$. In all these last cases the resistivity increases significantly, between $45 \%$ and $54 \%$ with respect to the sample $4 \mathrm{MK} .4 \mathrm{SF}$, which supposes a greater resistance to the penetration of chlorides and $\mathrm{CO}_{2}$ of this type of UHPC, and this translates in a greater durability. 


\section{Conclusions}

The use of additions and nanoaditions in concretes contribute significantly to the improvement of their mechanical properties, in addition to significantly decreasing the porosity of the UHPC matrix, and this is explained both by the pozzolanic reaction of these materials and by the filler effect associated with the size of its particles.

The use of additions and nanoaditions increases the formation of CSH gel while decreasing the amount of total portlandite during the hydration process of the UHPC matrix. The increase in the ratio of these two parameters is related to the increase in resistance to compression.

The use of nanosilica plays a very important role in reducing the percentage of large capillaries and increasing the percentage of small capillaries, which translates into high resistivity values associated with greater durability of the UHPC matrix.

Supplementary Materials: No supplementary material is available.

Author Contributions: Conceptualization, J.C.G. and A.E.; Data curation, J.P.; Funding acquisition, J.C.G. Investigation, J.P., J.C.G., A.E. and M. A.; Supervision, J.C.G.; Writing - original draft, J.P., J.C.G. and A.E.; Writing - review \& editing, J.C.G., A.E. and M.A.

Funding: This research was funded by the Ministry of Science of Spain by means of the Research Fund Project, grant number PID2019-108978RB-C31.

Acknowledgments: The authors gratefully acknowledge the financial support provided by the Ministry of Economy, Industry and Competitiveness of Spain by means of the Research Fund Project PID2019-108978RBC31. They also offer their gratitude to Calle 30 for supporting the Enterprise University Chair SIKA-UPM.

Conflicts of Interest: The authors declare no conflict of interest

\section{References}

1. M. J. Shannag, «High strength concrete containing natural pozzolan and silica fume.,» Cement and concrete composites, vol. 22, ํㅡ 6, pp. 399-406, 2000.

2. H. Yazıcl, «The effect of curing conditions on compressive strength of ultra high strength concrete with high volume mineral admixtures,» Building and environment, vol. 42, nº 5, pp. 2083-2089, 2007.

3. P. Richard, M. Cheyrezy, «Composition of reactive powder concretes,» Cement and concrete research, vol. 25, no 7, pp. 1501-1511, 1995.

4. F. De Larrar, T. Sedran, «Optimization of ultra-high-performance concrete by the use of a packing model,» Cement and Concrete Research, vol. 24, nº 6, pp. 997-1009, 1994.

5. A. E. Naaman y K. Wille, «The path to ultra-high performance fiber reinforced concrete (UHP-FRC): five decades of progress,» Proceedings of Hipermat, pp. 3-15, 2012.

6. A. E. Naaman y K. Wille, «Some Correlation Between High Packing Density, Ultra-High Performance, Flow Ability, and Fiber Reinforcement of a Concrete Matrix,» de $2^{\circ}$ Congresso Ibérico sobre betão auto-compactável, Guimarães, 2010

7. T. Hirschi y F. Wombacher, «Influence of different superplasticizers on UHPC,» de Proceedings of the Second International Symposium on Ultra High Performance Concrete, Kassel, 2008.

8. C. Shi, Z. Wu, J. W. D. Xiao, Z. Huang y Z. Fang, « A review on ultra high performance concrete: Part I. Raw materials and mixture design,» Construction and Building Materials, vol. 101, pp. 741-751, 2015.

9. T. Oertel, F. Hutter, R. Tänzer, U. Helbig y G. Sextl, «Primary particle size and agglomerate size effects of amorphous silica in ultra-high performance concrete,» Cement and Concrete Composites, vol. 37, pp. 6167, 2013.

10. A. E. Naaman y H. W. Reinhardt, «Proposed classification of HPFRC composites based on their tensile response,» Materials and structures, vol. 39, no 5, pp. 547-555, 2006.

11. D. Y. Yoo y N. Banthia, «Mechanical properties of ultra-high-performance fiber-reinforced concrete: A review,» Cement and Concrete Composites, vol. 73, pp. 267-280, 2016.

12. T. Oertel, U. Helbig, F. Hutter, H. Kletti y G. Sextl, «Influence of amorphous silica on the hydration in ultrahigh performance concrete,» Cement and Concrete Research, vol. 58, pp. 121-130, 2014.

13. N. K. Lee, K. T. Koh, M. O. Kim y G. S. Ryu, «Uncovering the role of micro silica in hydration of ultra-high performance concrete (UHPC),» Cement and Concrete Research, 104, pp. 68-79, 2018. 
14. D. Wang, C. Shi, Z. Wu, J. Xiao, Z. Huang y Z. Fang, « A review on ultra high performance concrete: Part II. Hydration, microstructure and properties,» Construction and Building Materials, vol. 96, pp. 368-377, 2015.

15. F. De Larrard y T. Sedran, «Mixture-proportioning of high-performance concrete,» Cement and concrete research, vol. 32, nº 11, pp. 1699-1704, 2002.

16. T. Stovall, F. De Larrard y M. Buil, «Linear packing density model of grain mixtures,» Powder technology, vol. 48, nº 1, pp. 1-12, 1986.

17. Andreasen, A.H.M. Ueber die Beziehung zwischen Kornabstufung und Zwischenraum in Produkten aus losen Körnern (mit einigen Experimenten). Kolloid-Zeitschrif 1930, 50, 217-228.

18. Funk, J.; Dinger, D. Predictive Process Control of Crowded Particulate Suspension, Applied to Ceramic Manufacturing; Kluwer Academic Press: Dordrecht, Netherlands, 1994.

19. EN 1015-3 Methods of test for mortar for masonry-Part 3: Determination of consistence of fresh mortar (by flow table). CEN: Brussels, Belgium, 1999.

20. EN 1015-11 Methods of test for mortar for masonry-Part 11: Determination of flexural and compressive strength consistence of hardened mortar. CEN: Brussels, Belgium, 2019.

21. ASTM E1131-08 Standard test method for compositional analysis by thermogravimetry. ASTM: West Conshohocken, PA, 19428-2959, USA, 2008.

22. UNE 83988-1 Concrete durability. Test methods. Determination of electrical resistivity Part1: Direct test. AENOR, Madrid, Spain, 2008.

23. Bhatty, J. Hydartion versus strength in a Portland cement developed frome domestic mineral wastes $-\mathrm{A}$ compartive study. Thermochim. Acta 1986, 106, 93-103.

24. Pane, I.; Hansen, W. Investigation of blended cement hydration by isothermal calorimetry and thermal analysis. Cem. Concr. Res. 2005, 35, 1155-1164.

25. Monteagudo, S.; Moragues, A.; Gálvez, J.; Casati, M.; Reyes, E. The degree of hydration assessment of blended cement pastes by differential thermal and thermogravimetric analysis. Morphological evolution of the solid phases. Thermochim. Acta 2014, 592, 37-51. 